\title{
Structural Basis of Enhanced Photoconversion Yield in Green Fluorescent Protein-like Protein Dendra2 ${ }^{\dagger}$
}

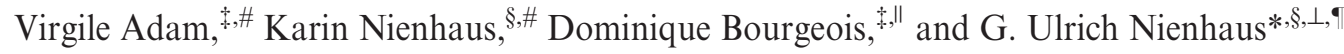 \\ ${ }^{\ddagger}$ European Synchrotron Radiation Facility, 6 Rue Jules Horowitz, BP 220, 8043 Grenoble Cedex, France, ${ }^{\S}$ Institute of Biophysics, \\ University of Ulm, Albert-Einstein-Allee 11, 89081 Ulm, Germany, "Laboratoire de Crystallogenèse et Crystallographie des \\ Protéines, IBS, Institut de Biologie Structurale Jean-Pierre Ebel, CEA, CNRS, Université Joseph Fourier, 41 Rue Jules Horowitz, \\ F-38027 Grenoble, France, ${ }^{\perp}$ Institute of Applied Physics and DFG-Center for Functional Nanostructures, University of \\ Karlsruhe (TH), 76128 Karlsruhe, Germany, and Department of Physics, University of Illinois at Urbana-Champaign, \\ 1110 West Green Street, Urbana, Illinois $61801{ }^{\#}$ V.A. and K.N. contributed equally to this work
}

Received March 6, 2009; Revised Manuscript Received April 16, 2009

\begin{abstract}
Dendra2 is an engineered, monomeric GFP-like protein that belongs to a subclass of fluorescent proteins undergoing irreversible photoconversion from a green- to a red-emitting state upon exposure to purple-blue light. This photoinduced process occurs only in the neutral state of the chromophore and is known to result from backbone cleavage accompanied by an extension of the delocalized $\pi$-electron system. We have measured the X-ray structure of the green species of Dendra2 and performed a comprehensive characterization of the optical absorption and fluorescence properties of the protein in both its green and red forms. The structure, which is very similar to those reported for the closely related proteins EosFP and Kaede, revealed a local structural change involving mainly Arg66 and a water molecule W4, which are part of a charged and hydrogen-bonded cluster of amino acids and water molecules next to the chromophore. Unlike in EosFP and Kaede, Arg66 of Dendra2 does not contribute to negative charge stabilization on the imidazolinone ring by hydrogen bonding to the imidazolinone carbonyl. This structural change may explain the blue shift of the absorption and emission bands, as well as the markedly higher $\mathrm{p} K \mathrm{~s}$ of the hydroxyphenyl moiety of the chromophore, which were determined as 7.1 and 7.5 for the green and red species, respectively. The action spectrum of photoconversion coincides with the absorption band of the neutral species. Consequently, its 20-fold enhancement in Dendra2 at physiological $\mathrm{pH}$ accounts for the higher photoconversion yield of this protein as compared to EosFP.
\end{abstract}

The discovery of the green fluorescent protein from the jellyfish Aequorea victoria (avGFP) and its further development into a versatile research tool in the life sciences have enabled a vast array of novel approaches to gain insights into biomolecular processes, especially in living cells and organisms $(1-4)$. Consequently, it was not a surprise that the Nobel Prize in Chemistry 2008 was awarded to Shimomura, Chalfie, and Tsien for the discovery, cloning, and development of avGFP (5-8). Fluorescent proteins $(\mathrm{FPs})^{1}$ from the GFP family have also been found in many other marine animals $(9-13)$, some of which exhibited entirely new properties that are beneficial for imaging applications, including red-shifted fluorescence and photoactivation. Currently, the search for novel GFP-like proteins is ongoing, driven by the

\footnotetext{
†This work was supported by the Deutsche Forschungsgemeinschaft (DGF) and the State of Baden-Württemberg through the DFG-Center for Functional Nanostructures (CFN), by DFG grants NI 291/9 and SFB 497, and by the Fonds der Chemischen Industrie (to G.U.N.). D.B. acknowledges support by the Agence Nationale de la Recherche (ANR07-BLAN-0107-01).

*To whom correspondence should be addressed. E-mail: uli@uiuc. edu. Phone: + 49 (0)731 502 3050. Fax: + 49 (0)731 5023059.

${ }^{1}$ Abbreviations: FP, fluorescent protein; GFP, green fluorescent protein; $p$-HBI, 4-(p-hydroxybenzylidene)-5-imidazolinone; ESPT, excited state proton transfer.
}

persistent need for advanced and specialized fluorescence labels for cellular imaging.

Although FPs are all structurally similar, their essential optical properties including absorption and emission spectra and fluorescence quantum yields vary greatly $(1,2)$. Their polypeptide chain consists of 220-240 amino acid residues and folds into a rigid, 11-stranded $\beta$-barrel, with a central helix along its axis $(14,15)$. In the center of the barrel, a fluorescent chromophore forms from the tripeptide X-Tyr-Gly in a posttranslational selfmodification process that requires nothing else but molecular oxygen (16). The first amino acid, X, may be any amino acid, but the second and third amino acids, tyrosine and glycine, are strictly conserved in nature. The GFP chromophore, 4-( $p$-hydroxybenzylidene)-5-imidazolinone ( $p$-HBI), is generated by sequential main-chain cyclization and oxidation-dehydration steps (17). For a number of FPs, additional chemical modifications of the chromophore result in substantial changes of the optical properties. Such modifications may occur spontaneously as, for example, the oxidation of the $\mathrm{N} \alpha-\mathrm{C} \alpha$ bond of amino acid $\mathrm{X}$ (18), yielding the red-emitting 2-imino-5-(4-hydroxybenzylidene)imidazolinone chromophore of orange and red FPs such as DsRed (19) and eqFP611 (20). Other modifications are photoinduced and require absorption of a photon of suitable energy. 
Photoactivation offers an external control over the intensity or color of the fluorescence emission and allows a subset of proteins to be tagged and their subsequent dynamics to be followed within cells, tissues, or entire organisms $(21,22)$. Moreover, photoactivation forms the basis of novel microscopy concepts featuring image resolutions substantially better than the Abbe (diffraction) limit (23-26).

Two types of photoactivation are being distinguished. Reversible photoswitching between a fluorescent and a nonfluorescent species involves isomerization of the chromophore, whereas irreversible photoconversion arises from a light-driven covalent modification. For a particular class of photoconvertible FPs, which comprises, among others, EosFP (27), mcavRFP (28), Kaede (29), KikGR (30), and Dendra (31), irradiation into the $\sim 400 \mathrm{~nm}$ band of the neutral chromophore leads to cleavage of the backbone between the $\mathrm{N} \alpha$ and $\mathrm{C} \alpha$ atoms of amino acid $\mathrm{X}$, which is always a histidine in these FPs (32-35). Concomitantly, a double bond forms between its $\mathrm{C} \alpha$ and $\mathrm{C} \beta$ atoms, so that the chromophore $\pi$-conjugation is extended to the histidine imidazole ring via an all-trans ethenylene moiety. The new chromophore, 2-[(1E)-2-(5-imidazolyl)ethenyl]-4-( $p$-hydroxybenzylidene)-5-imidazolinone, emits fluorescence in the orange-red region of the spectrum.

In this work, we report on structure-function relationships of Dendra2, a variant of Dendra (dendGFP), which was originally cloned from the soft coral Dendronephthya sp. from the Anthozoa subclass Alcyonaria (31). Like other naturally occurring anthozoan FPs, dendGFP oligomerizes and forms both dimers and tetramers. Dendra2 is an engineered, monomeric variant of dendGFP that was advertised as being photoconvertible by blue $(488 \mathrm{~nm})$ light (36). Monomerization, which was achieved by the three point mutations Asn121Lys, Met123Thr, and Tyr188Ala (Figure S1, Supporting Information), is crucial for applications as a fusion marker, for which the FP-encoding sequence is linked to the DNA of a protein of interest, thereby adding a fluorescent protein tag for protein visualization and tracking. Dendra2 and EosFP share $69 \%$ identical amino acid residues. The X-ray structure of green Dendra2 is overall highly similar to that of EosFP (32) but reveals structural differences close to the chromophore. The differences in the optical properties and photoconversion efficiency of Dendra2 and EosFP can be rationalized on the basis of these structural changes.

\section{MATERIALS AND METHODS}

Protein Expression and Purification. The pDendra2-B vector was purchased from Evrogen (Moscow, Russia). The sequence coding for Dendra2 was subcloned into a pQE32 expression vector (Qiagen, Hilden, Germany). Escherichia coli strain M15[pREP4] was transformed with the recombinant plasmid; protein expression was induced by IPTG. The soluble protein was kept in the dark during purification with a TALON metal affinity resin (BD Biosciences Clontech, Palo Alto, CA). The fraction containing the protein was dialyzed to remove the imidazole present in the elution buffer.

Crystallization. Crystals of Dendra2 were grown at $20^{\circ} \mathrm{C}$ by mixing $2 \mu \mathrm{L}$ of a solution of Dendra2 at $17.4 \mathrm{mg} / \mathrm{mL}$ and $2 \mu \mathrm{L}$ of $30 \%$ PEG 4000, $0.2 \mathrm{M}$ magnesium nitrate, and $0.1 \mathrm{M}$ Tris- $\mathrm{HCl}$, $\mathrm{pH} 8.5$, using the hanging-drop vapor-diffusion method. Because the initial crystals diffracted poorly, they were crushed and, using the streak seeding method, transferred into preequilibrated crystallization drops of Dendra2 and a solution containing 32\% PEG 3350, 0.1 M magnesium nitrate, and 0.1 M Tris-HCl,
pH 8.8. A few single crystals diffracting to $2.0 \AA$ resolution appeared after several weeks. Due to the poor reproducibility of the procedure, crystals of Dendra2 in its red form could not be obtained. For X-ray data collection, crystals of the green form were rapidly transferred to a cryoprotectant solution $(10 \%$ glycerol/32\% PEG 3350, 0.1 M magnesium nitrate, 0.1 M Tris$\mathrm{HCl}, \mathrm{pH} 8.8)$ and flash-frozen in a stream of nitrogen gas.

$X$-ray Data Collection. X-ray diffraction experiments were performed at $100 \mathrm{~K}$ on beamline ID14-4 $(\lambda=0.939 \AA)$ at the European Synchrotron Radiation Facility (ESRF, Grenoble, France). We observed that the diffraction quality of the Dendra2 crystals decayed rapidly upon X-ray exposure. Thus, two crystals were used, and a composite data collection strategy was employed for each of them so as to maximize the completeness (37). After individual integration of the two data subsets with the program XDS (38), they were scaled and merged with the program XSCALE (38). The crystal structure was solved by molecular replacement with Phaser (39), using the coordinates of wild-type EosFP (PDB ID code 1ZUX (32)) as a search model. Crystallographic refinement was performed with Refmac (40) and COOT (41). Chromophore restraints were generated in Libcheck (42) using idealized coordinates from the Hic-Up database (43). The atomic coordinates and structure factors have been deposited in the Protein Data Bank (www.pdb.org, accession code 2VZX).

Optical Spectroscopy. To measure UV/visible spectra, Dendra2 was dissolved to final concentrations of $\sim 10 \mu \mathrm{M}$ (absorption) and $1 \mu \mathrm{M}$ (fluorescence) in $100 \mathrm{mM}$ potassium citrate/ potassium phosphate $(\mathrm{pH}<5)$, potassium phosphate $(5<\mathrm{pH}$ $<8.5$ ), and potassium carbonate buffers $(\mathrm{pH}>8.5)$, respectively. Absorption spectra were collected at $20^{\circ} \mathrm{C}$ on a Cary 1 spectrophotometer (Varian, Darmstadt, Germany) at a resolution of $1 \mathrm{~nm}$. Fluorescence excitation and emission spectra were measured with a SPEX Fluorolog II spectrofluorometer (Spex Industries, Edison, $\mathrm{NJ}$ ) with the excitation line width set to $2.2 \mathrm{~nm}$; the emission was also recorded with $2.2 \mathrm{~nm}$ resolution. Emission spectra were corrected for the detector response.

\section{RESULTS}

Overall Structure of Dendra2. Dendra2 crystallized in the $P 1$ space group. The structure was determined to $2.0 \AA$ resolution, with a final $R_{\text {cryst }}$ of $21.4 \%$ and $R_{\text {free }}$ of $26.9 \%$ (Table 1 ). The unit cell contains eight protein chains (Figure 1), with little deviation between them (the average rmsd between two protomers in the asymmetric unit is $0.72 \pm 0.21 \AA$ ). Most amino acids are visible in the electron density, unlike the hexahistidine tag preceding the $\mathrm{N}$-terminus, which apparently is highly disordered. The typical GFP-like $\beta$-barrel fold of Dendra2 is shown in Figure $2 \mathrm{~A}$, with the nearly planar chromophore (Table 1 ) held rigidly in the center and shielded from the bulk solvent by the $\beta$-barrel and several interconnecting loops.

In a typical tetrameric anthozoan $\mathrm{FP}$, each protomer, denoted $\mathrm{A}, \mathrm{B}, \mathrm{C}$, and $\mathrm{D}$, is in contact with two neighboring ones so that two subunit interfaces can be distinguished (denoted by $\mathrm{A} / \mathrm{B}$ and $\mathrm{A} / \mathrm{C})(44)$. The $\mathrm{A}$ and $\mathrm{B}$ barrels are oriented in an antiparallel fashion, which produces a meshlike layering of the $\beta$-sheets in the $\mathrm{A} / \mathrm{B}$ interface that is mainly stabilized by hydrophobic interactions. By contrast, in the more hydrophilic $\mathrm{A} / \mathrm{C}$ interface, the neighboring barrels are rotated against each other to allow for perfect stacking of their $\beta$-sheets. Dendra2 was reported to be monomeric in solution (36), and its monomeric state may be responsible for the enormous difficulties we encountered 
Table 1: Data Collection, Refinement, and Structure Quality Statistics of Dendra2

PDB accession code

Data Collection Statistics

space group beamline

wavelength $(\AA)$

cell dimensions

$a, b, c(\AA)$

$\alpha, \beta, \gamma(\mathrm{deg})$

resolution $(\AA)$

$R_{\text {merge }}(\%)^{b}$

mean $I / \sigma(I)$

completeness $(\%)$

no. of total reflections

no. of unique reflections

ESRF/ID14-4
0.939
$P 1$

$71.26,76.85,92.50$

$90.05,108.17,106.58$

$33.5-2.0(2.1-2.0)^{a}$

4.7 (17.4)

$12.15(4.42)$

$94.1(94.5)$

$220830(30255)$

113215 (16379)

Refinement

\section{$R_{\text {cryst }} / R_{\text {free }}{ }^{c}$}

no. of water

average $B$ factor $\left(\AA^{2}\right)$

chromophore planarity ${ }^{d}$

dihedral angle 1 (deg)

dihedral angle 2 (deg)

rms deviation from ideality

bond lengths $(\AA)$

bond angles (deg)

$0.214 / 0.269$

14474

1276

21.8

$3.2 \pm 1.1$

$8.5 \pm 3.6$

0.009

1.421 no. of protein atoms
2 VZX
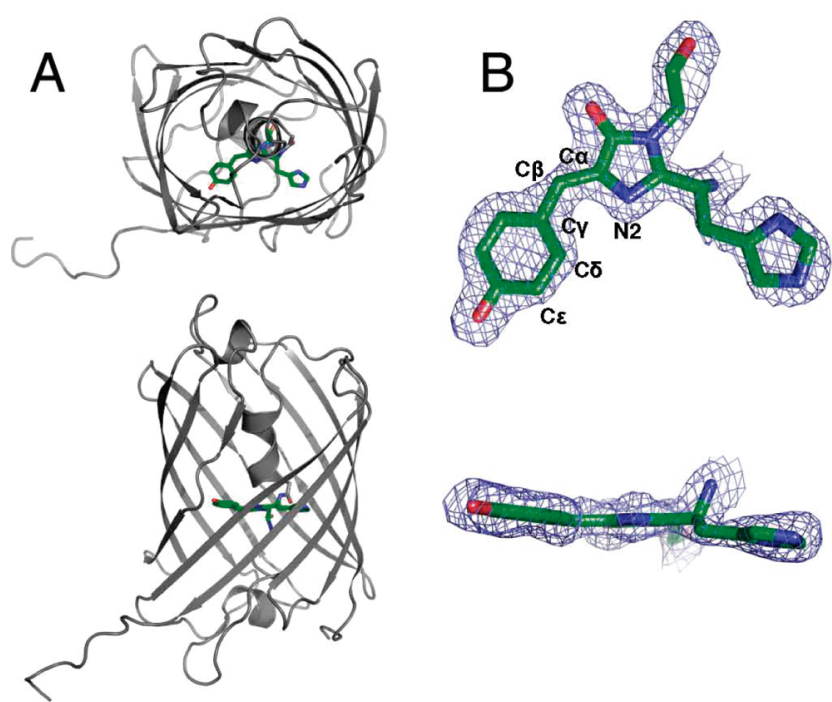
The $2 F_{\mathrm{o}}-F_{\mathrm{c}}$ electron density map is contoured at $1.5 \sigma$.
${ }^{a}$ Values in parentheses refer to the highest resolution shell. ${ }^{b} R_{\text {merge }}=$ $\sum_{j} \sum_{h}\left|I_{h, j}-\left\langle I_{h}\right\rangle\right| / \sum_{j} \sum_{h} I_{h, j}{ }^{c} R_{\text {cryst }}=\sum_{h}\left|F_{\mathrm{o}}-F_{\mathrm{c}}\right| / \sum_{h} F_{\mathrm{o}} . R_{\text {free }}$ is calculated with a small fraction $(5 \%)$ of reflections chosen to be part of a test group. ${ }^{d}$ Chromophore planarity was assessed by the measurement of the average dihedral angles linking atoms $\mathrm{N} 2-\mathrm{C} \alpha-\mathrm{C} \beta-\mathrm{C} \gamma$ (dihedral angle 1) and $\mathrm{C} \alpha-\mathrm{C} \beta-\mathrm{C} \gamma-\mathrm{C} \delta$ (dihedral angle 2) of the chromophore.

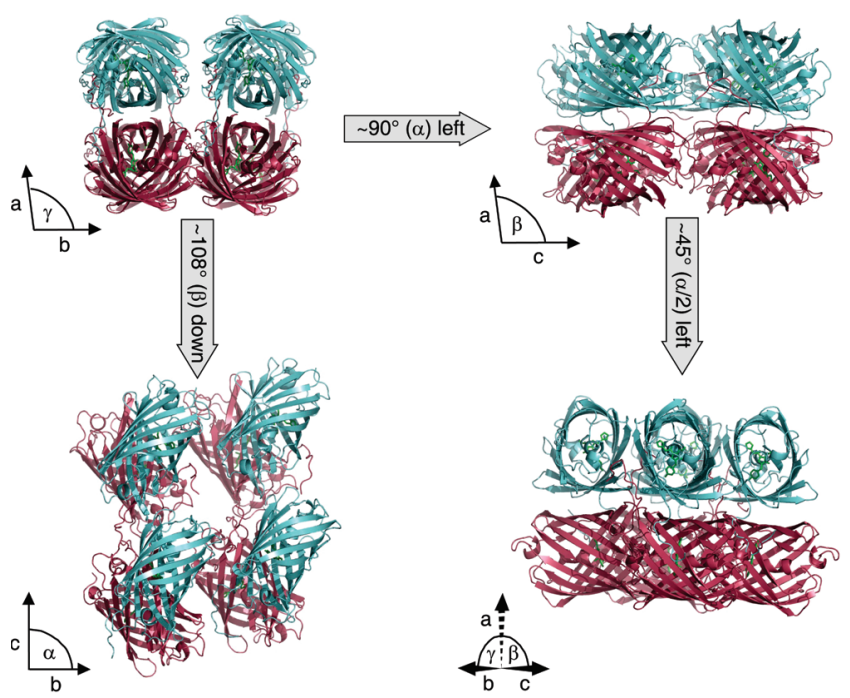

FIGURE 1: Crystal packing of Dendra2, shown along (A) the unit cell axis $c,(\mathrm{~B})$ the axis $b,(\mathrm{C})$, the axis $a$, and (D) at half the angle $\left(\sim 45^{\circ}\right)$ between the $b$ and $c$ axes. In each unit cell, eight molecules are arranged in four weak dimers; the protomers are colored in cyan and prune. Chromophores are shown as green sticks.

in growing crystals. In crystals, the Dendra2 protomers are observed to form $\mathrm{A} / \mathrm{C}$ dimers because residual stabilizing interactions promote interface formation at the high protein concentrations present during crystal growth. Two salt bridges exist between Arg149 and Glu96 of each monomer (Figure 3), as in the EosFP $\mathrm{A} / \mathrm{C}$ interface (12). (Here and throughout this paper, we report residue numbers according to Dendra2, as
Figure 2: (A) Top and side views of the overall fold of a Dendra2 monomer in cartoon representation, with the embedded chromophore shown as sticks. (B) Top and side views of the chromophore.

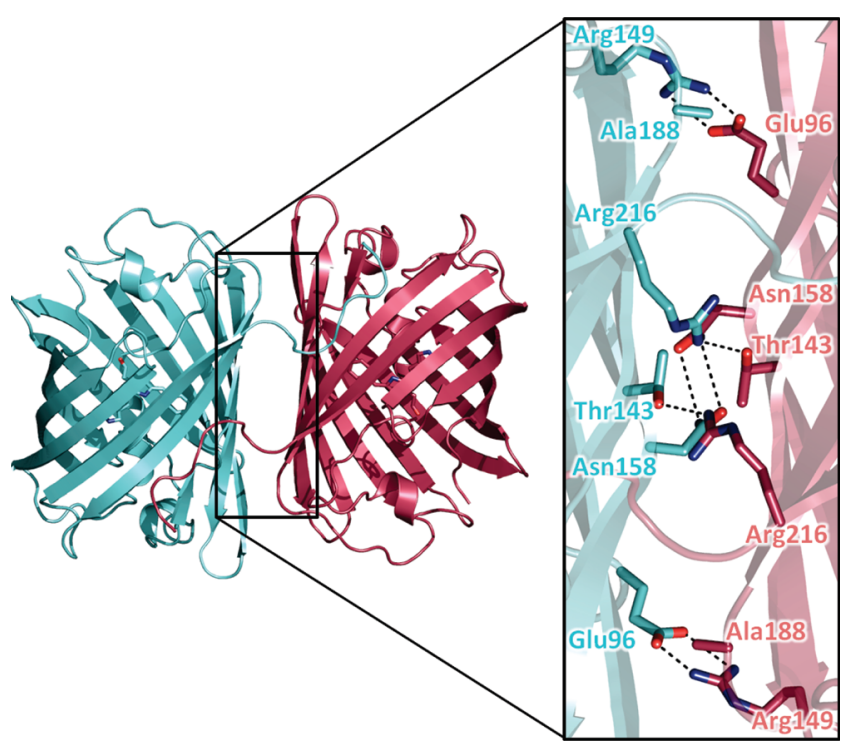

Figure 3: (A) Overview of the dimeric structure. (B) Close-up view of the interface. The residues involved in the strongest interactions are shown as sticks.

shown in the alignment in Figure S1, Supporting Information.) Additional interface stabilization is provided by hydrogen bonds within a cluster consisting of Thr143, Asn158, and Arg216 of both monomers. In EosFP, there is also a hydrogen-bonded cluster consisting of Thr143, Arg170, and Asp156. In EosFP, DsRed, and eqFP611, three aromatic residues at positions 188, 190, and 212 of the $\mathrm{A}$ and $\mathrm{C}$ chains form an additional hydrophobic patch. To generate the monomeric variant Dendra2, one of these residues (Tyr188) was replaced by alanine in the dendGFP sequence, which apparently was sufficient to destabilize the interface at low protein concentrations (36).

A typical A/B-type interface is absent in the Dendra2 crystal. Each pair of cyan and prune barrels in the lower left panel of Figure 1 represents an $\mathrm{A} / \mathrm{C}$ dimer. Thus, $\mathrm{A} / \mathrm{B}$ dimers would form between barrels of the same color. However, the cyan (prune) barrels plotted side by side are oriented in a parallel fashion, whereas the cyan (prune) barrels plotted above each other (within a column) are oriented in an antiparallel fashion but do not share 
an interface. Compared with the wild-type protein, Dendra 2 has two point mutations that were introduced to disrupt this interface, Asn121Lys and Met123Thr. The same residues were also modified to destroy the A/B interface in other anthozoan FPs, for example, Val123Thr in EosFP (12) and Thr121Arg and Val123Thr in eqFP611 (44). The sequence alignment of EosFP and Dendra2 shows that the interface-forming residues of these two proteins are identical except for position 121, at which the histidine of EosFP is replaced by a lysine in Dendra2. In EosFP, the His121 side chains of protomers A and B are $\pi$-stacked and, thereby, help to stabilize the interface. In Dendra2, the long lysine side chain may generate steric conflicts, and moreover, the charged amino groups repel each other, so that the interface is completely destabilized.

Chromophore Environment. In all green-to-red photoconvertible FPs, the chromophore forms from the tripeptide HisTyr-Gly. Indeed, any amino acid replacement of the histidine abolishes photoconversion, suggesting that the imidazole side chain is crucially involved in the photochemical process (32). The amino acid preceding the chromophoric triad is a phenylalanine in many FPs including EosFP, Kaede, eqFP611, and avGFP. Interestingly, it is a valine (Val61) in Dendra2. Multiple hydrogen bonds and van der Waals interactions restrain the chromophore in the center of the $\beta$-can in an essentially coplanar arrangement of the aromatic imidazolinone and phenyl rings (Figure 2, Table 1). The cis conformation of the $p$-HBI chromophore is stabilized by hydrogen bonds from the tyrosine oxygen atom to the Ser142 oxygen $(2.7 \AA)$ and to a water molecule (W5, $2.8 \AA$ ). The carbonyl oxygen of the imidazolinone ring hydrogen-bonds with the side chain of $\operatorname{Arg} 91(2.9 \AA)$.

Glu144, His193, Glu211, Arg66, water molecule W4, and Tyr177 form a planar network beneath the chromophore stabilized by hydrogen bonds and Coulomb interactions (Figure 4A). Similar polar networks, which may provide a rigid scaffold restricting chromophore dynamics, have been noticed for a variety of anthozoan FPs including DsRed $(18,19)$, eqFP611 $(20,45)$, zFP538 (46), and amFP486 by Henderson and Remington (47). The Arg66 side chain is held in place by a salt bridge from $\mathrm{N} \eta_{1}$ to Glu211, a hydrogen bond between $\mathrm{N} \eta_{1}$ and $\mathrm{W} 3$, and another hydrogen bond from $\mathrm{N} \eta_{2}$ to W4. It is further stabilized by a weak hydrogen bond between its $\mathrm{N} \varepsilon$ and the side chain hydroxyl of Thr69 (Figure 5). The same Arg66 stabilization and orientation has been found in amFP486 (47), mKO (48), and mTFP1 (49).

The chromophore environment of EosFP is shown in Figure 4B for comparison. A significant structural difference in the immediate chromophore environment is obvious; namely, water W4 and the Arg66 guanidino group have exchanged their locations. The completely different orientation of the Arg66 side chain in EosFP may originate from the replacement of Thr69 by Ala69 (Figure 5). The small aliphatic side chain cannot form a hydrogen bond to $\mathrm{N} \varepsilon$ of $\mathrm{Arg} 66$. This interaction is also absent in Kaede (35) and KikGR (30), carrying a valine and an alanine at position 69, respectively; their Arg66 side chains also adopt the EosFP-like position. As a consequence, the carbonyl oxygen of the imidazolinone is only $2.9 \AA$ away from the $\mathrm{N} \eta_{1}$ atom of $A r g 66$ in EosFP ( $2.8 \AA$ in KikGR, $2.8 \AA$ in Kaede), so that an additional hydrogen bond is established. In contrast, the distance between the Arg66 side guanidine moiety and the carbonyl oxygen is $3.9 \AA$ in Dendra2 (3.9 $\AA$ in mTFP1, 3.6 ̊ in amFP486, $4 \AA$ in mKO) and thus too long for hydrogen bonding. As will be described below, this structural finding bears consequences for the optical properties of Dendra2.

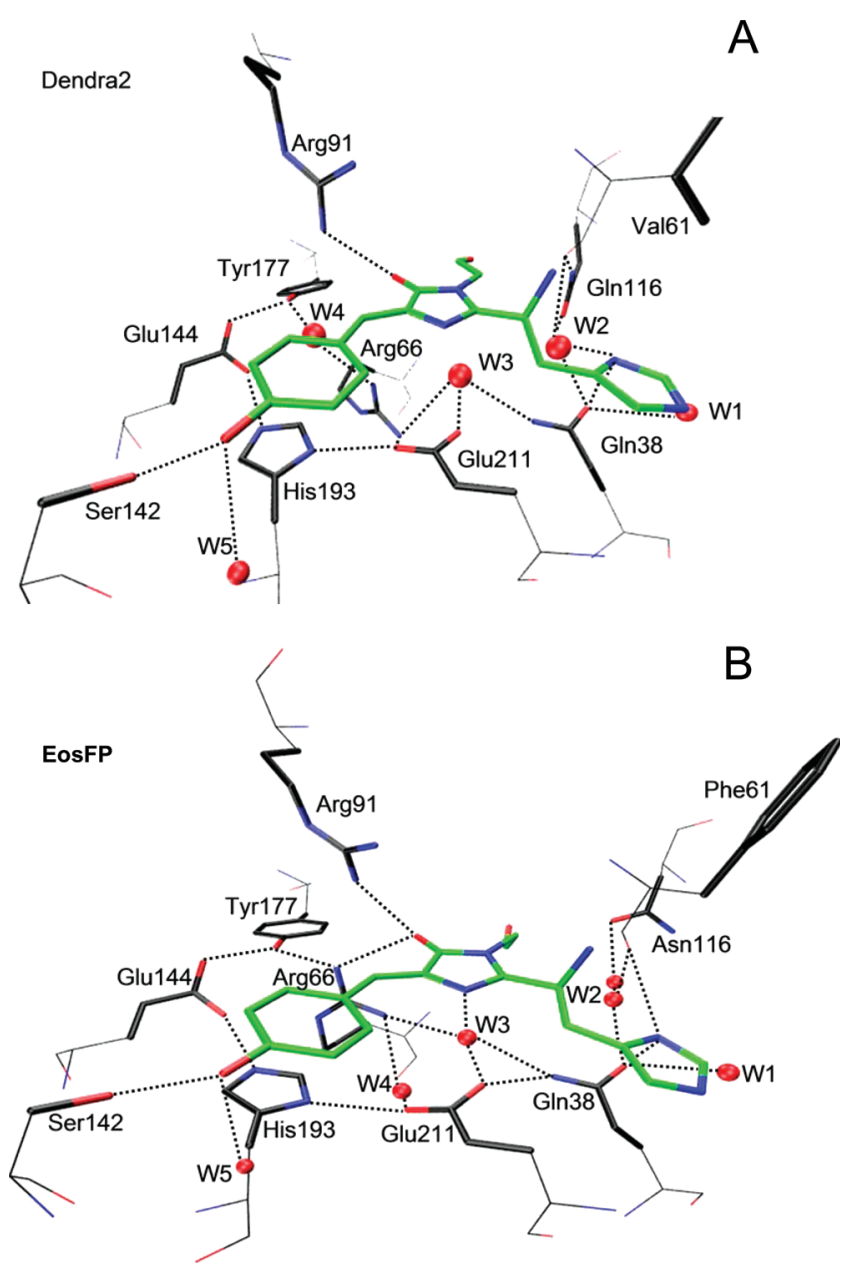

FIgURE 4: Chromophore environment in (A) Dendra2 and (B) EosFP. Water molecules are shown as red spheres. Hydrogen bonds are indicated by dotted lines. Color coding: carbon, black; oxygen, red; nitrogen, blue). The chromophore is shown with green carbon atoms.

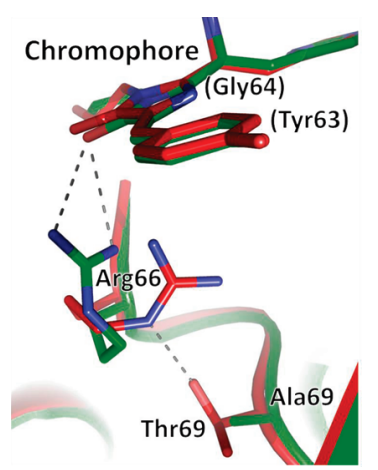

FIgURE 5: In Dendra2 (carbon atoms shown in red), the side chains of Arg66 and Thr69 are connected by a hydrogen bond. In EosFP (carbon atoms shown in green), there is no interaction between the Arg66 and Ala69 side chains.

For light-induced generation of the red 2-[(1E)-2-(5-imidazolyl)ethenyl]-4-(p-hydroxybenzylidene)-5-imidazolinone chromophore, two key amino acids have been identified, Glu211 and His62. Glu211 has been suggested to act as a base for proton abstraction from His62-C $\beta$, and indeed, replacement of Glu211 by Gln results in complete loss of photoconversion in EosFP (12) and Kaede (35). Likewise, mutation of His62 in Kaede (34) and EosFP (27) to another amino acid completely abolishes formation of the red chromophore. Based on the X-ray structures of 
green and red EosFP, we had suggested that the His62 imidazolium may donate a proton to the Phe61 carbonyl, thus rendering the peptide group between Phe61 and His62 an ideal carboximidic leaving group in the $\beta$-elimination reaction (32). The distances between His62-N $\delta$ and the Phe61 carbonyl are $3.3 \AA$ in EosFP (32) and $3.2 \AA$ in Kaede (35). In the Dendra2 structure, the corresponding distance between the His62-N $\delta$ and the Val61 carbonyl is significantly larger, $3.8 \AA$. However, structural readjustments could occur in the excited state that strengthen the interaction and allow proton transfer to take place.

Absorption Spectra of Green Dendra2. The pH-dependent absorption spectra of green Dendra2 are shown in Figure 6A (for additional spectra, see Figure S2, Supporting Information). The two bands at $\sim 385$ and $\sim 493 \mathrm{~nm}$ are denoted as A and B bands, respectively; they are associated with the neutral (phenol) and anionic (phenolate) forms of the chromophore $(16,50,51)$. The exact peak positions vary with $\mathrm{pH}$ and are compiled in Table 2 . (The near-UV band at $280 \mathrm{~nm}$ results from aromatic amino acid side chain absorption.) With increasing $\mathrm{pH}$, the $\mathrm{B}$ band gains amplitude at the expense of the $\mathrm{A}$ band. The $\mathrm{pH}$ dependence of the transition can be modeled by a single-site protonation, with $\mathrm{p} K=7.1 \pm 0.1$ (Figure 6B). This value is thus significantly higher than the corresponding ones of EosFP $(\mathrm{p} K=5.8(27))$ and Kaede ( $\mathrm{p} K=5.6(29)$ ). For EosFP, we observed that replacement of Ala69 by threonine shifted the chromophore $\mathrm{p} K$ to $\sim 7$ (data not shown). Consequently, stabilization of the proton on the phenyl moiety in Dendra2, which amounts to $\sim 7.5 \mathrm{~kJ} / \mathrm{mol}$, may arise from the altered Arg66 side chain conformation due to its interaction with Thr69. The lack of hydrogen bonding between Arg66 and the carbonyl oxygen of the imidazolinone ring results in reduced negative charge stabilization on the ring. The concomitantly enhanced charge density on the hydroxyphenyl moiety may contribute to the stronger proton binding affinity of Dendra2. The same structural difference can also explain the blue shift of the absorption maximum of the anionic green chromophore $(492 \mathrm{~nm})$ in Dendra2 with respect to EosFP $(506 \mathrm{~nm})$. Upon electronic excitation of the $p$-HBI chromophore, the electron density is known to shift from the phenyl to the imidazolinone $(16,52)$. The missing charge stabilization on the imidazolinone by Arg66 in Dendra will, therefore, raise the energy of the excited state with respect to the ground state, resulting in a blue shift of the transition. In complete agreement with this explanation, the Thr69Ala mutation indeed turns Dendra2 into a more EosFP-like protein, with the B band red shifted to $502 \mathrm{~nm}$ (Table 3), whereas the Ala69Thr mutation of EosFP elicits the opposite effect (data not shown).

Interestingly, in the high- $\mathrm{pH}$ regime $(\mathrm{pH}>10)$, the population ratio between the neutral and the anionic chromophore is observed to shift back to the protonated species (Figure S2, Supporting Information). Most likely, the water molecule W5 (Figure 4) that, together with Ser142, stabilizes the negative charge on the phenolate oxygen is exchanged by a hydroxyl ion at high $\mathrm{pH}$, so that the protonated hydroxyphenyl ring becomes energetically favored. At $\mathrm{pH} \mathrm{13,} \mathrm{a} \mathrm{new} \mathrm{absorption} \mathrm{band} \mathrm{at}$ $446 \mathrm{~nm}$ appears at the expense of both the A and B bands (dotted line in Figure 6A). For avGFP, a band at a similar position (448 nm) was reported upon base denaturation (53), whereas the synthetic analogue of the GFP chromophore, 4-hydroxybenzylidene-2,3-dimethylimidazolinone (HBDI), has an absorption maximum at $425 \mathrm{~nm}$ in $\mathrm{NaOH}$. In Dendra2, the $446 \mathrm{~nm}$ band subsequently loses intensity, and concomitantly, a new band appears at $347 \mathrm{~nm}$ (gray line in Figure 6A). An isosbestic point
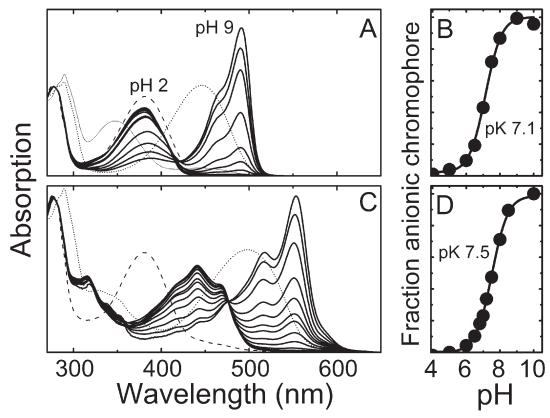

Figure 6: Absorption spectra of (A) green and (C) red Dendra2, recorded from $\mathrm{pH} 4$ to $\mathrm{pH} 10$. The spectra of acid/base-denatured Dendra2 are included as dashed/dotted lines. (C) The gray line represents the species which develops at $\mathrm{pH} 13$ with time. (B, D) Symbols: Fraction of deprotonated chromophores as a function of $\mathrm{pH}$. Fit (lines) of the data to a Henderson-Hasselbalch relation.

\begin{tabular}{|c|c|c|c|c|c|}
\hline & \multirow[b]{2}{*}{$\mathrm{pH}$} & \multicolumn{2}{|c|}{ neutral chromophore } & \multicolumn{2}{|c|}{ anionic chromophore } \\
\hline & & $\begin{array}{c}\lambda_{\max a b s} \\
\left(\mathrm{~nm} / \mathrm{cm}^{-1}\right)\end{array}$ & $\begin{array}{c}\lambda_{\max e m} \\
\left(\mathrm{~nm} / \mathrm{cm}^{-1}\right)\end{array}$ & $\begin{array}{c}\lambda_{\max \text { abs }} \\
\left(\mathrm{nm} / \mathrm{cm}^{-1}\right)\end{array}$ & $\begin{array}{c}\lambda_{\max \mathrm{em}} \\
\left(\mathrm{nm} / \mathrm{cm}^{-1}\right)\end{array}$ \\
\hline \multirow[t]{7}{*}{ green } & 1 & $381.7 / 26200^{a}$ & - & - & - \\
\hline & 4 & $378.8 / 26400$ & $454^{b}$ & - & - \\
\hline & 7 & $383.1 / 26100$ & - & $460.8 / 21700$ & $542.0 / 18450$ \\
\hline & & & & $492.6 / 20300$ & $504.5 / 19820$ \\
\hline & 9 & $387.6 / 25800$ & - & $463.0 / 21600$ & $542.0 / 18450$ \\
\hline & & & & $495.1 / 20200$ & $504.5 / 19820$ \\
\hline & 13 & - & - & $446(347)$ & - \\
\hline \multirow[t]{10}{*}{ red } & 1 & $381.7 / 26200$ & - & - & - \\
\hline & 4 & $393.7 / 25400$ & $609.7 / 16400$ & & \\
\hline & & $414.9 / 24100$ & $561.8 / 17800$ & & \\
\hline & & $440.5 / 22700$ & $516.8 / 19350$ & & \\
\hline & & $471.7 / 21200$ & $480.8 / 20800$ & & \\
\hline & 10 & & & $478.5 / 20900$ & $675.7 / 14800$ \\
\hline & & & & $515.5 / 19400$ & $619.2 / 16150$ \\
\hline & & & & $555.6 / 18000$ & $570.5 / 17530$ \\
\hline & 12 & & & 499 & \\
\hline & & & & 347 & \\
\hline
\end{tabular}

${ }^{a}$ If value is given in both $\mathrm{nm}$ and $\mathrm{cm}^{-1}$, peak position was determined by calculating the second derivatives in the wavenumber regime. Estimated error: $\pm 50 \mathrm{~cm}^{-1}$. ${ }^{b}$ If value is given only in $\mathrm{nm}$, peak position was obtained by fitting a Gaussian line to the spectrum. Estimated error: $\pm 0.5 \mathrm{~nm}$.

at $384 \mathrm{~nm}$ indicates a two-state transition (Figure S2, Supporting Information); the marked decrease of the wavelength indicates a less delocalized $\pi$-electron system in this state. This process is irreversible, suggesting that the chromophore has been destroyed.

The acid-denatured protein at $\mathrm{pH} 1$ shows an absorption band at $381.7 \mathrm{~nm}$ (dashed line in Figure 6A). It is essentially identical to the A band, implying that the neutral green chromophore remains intact even under harsh acidic conditions. HBDI has an absorption maximum at $389 \mathrm{~nm}$ upon acidification, which further supports this assertion (54).

In addition to the $\mathrm{pH}$-dependent changes in the relative areas of the A and $\mathrm{B}$ bands, intrinsic band shifts are visible. Between pH 2 and 9, the A band shifts to the red, from 381.7 to $387.6 \mathrm{~nm}$, and this $\mathrm{pH}$ dependence can be described by a $\mathrm{p} K=7.1 \pm 0.1$. A small red shift of the B band from $492.6 \mathrm{~nm}$ (shoulder at $460.8 \mathrm{~nm})$ at $\mathrm{pH} 7$ to $495.1 \mathrm{~nm}(463.0 \mathrm{~nm})$ at $\mathrm{pH} 9$, which is described by $\mathrm{p} K=8.0 \pm 0.1$, is barely visible in the spectra. These band shifts reflect an altered charge distribution around the chromophore, probably caused by deprotonation of an amino acid near the chromophore. 
Table 3: Key Properties Related to Blue Shift of Select FPs

\begin{tabular}{|c|c|c|c|c|c|c|c|}
\hline FP species & PDB ID & ref & $\begin{array}{c}\text { chromophore } \\
\mathrm{p} K\end{array}$ & $\begin{array}{c}\text { distance } \\
\mathrm{N} \eta_{1 / 2 \text { Arg91 }}- \\
\mathrm{O}_{\text {imidazolinone }}(\AA)\end{array}$ & residue 69 & $\begin{array}{c}\text { green } \\
\text { chromophore } \\
\lambda_{\mathrm{exc}} / \lambda_{\mathrm{em}}(\mathrm{nm})\end{array}$ & $\begin{array}{c}\text { modified } \\
\text { chromophore } \\
\lambda_{\text {exc }} / \lambda_{\mathrm{em}}(\mathrm{nm})\end{array}$ \\
\hline Dendra & $2 \mathrm{VZX}$ & & $7.1 / 7.5$ & $2.9 / 3.6$ & Thr & $492 / 505$ & $555 / 571$ \\
\hline zFP538 (immature green) & 1XAE & 46 & - & - & Thr & $-/ 506$ & - \\
\hline mTFP1 & 2HQK & 49 & 4.3 & $3.0 / 3.6$ & Thr & $462 / 492$ & - \\
\hline amFP486 & $2 \mathrm{~A} 46$ & 47 & $<5$ & $2.7 / 3.6$ & Thr & $454 / 486$ & - \\
\hline $\mathrm{mKO}$ & $2 \mathrm{ZMU}$ & 48 & 5.0 & $2.8 / 3.6$ & Thr & - & $548 / 559$ \\
\hline cmFP512 & $2 \mathrm{C} 9 \mathrm{~J}$ & 68 & $\sim 4$ & $2.7 / 2.9$ & Thr & $502 / 512$ & - \\
\hline Ala142Ser cmFP512 & - & 68 & $<5$ & - & Thr & $486 / 507$ & - \\
\hline EosFP & 1ZUX & 32 & 5.8 & $2.6 / 3.7$ & Ala & $506 / 516$ & $569 / 581$ \\
\hline Thr69Ala Dendra2 & - & & - & - & Ala & $502 / 515$ & $565 / 578$ \\
\hline Kaede & 2GW3 & 35 & 5.6 & $2.7 / 3.7$ & Ala & $508 / 518$ & $570 / 582$ \\
\hline mKikGR & $2 \mathrm{DDC}$ & 30 & $6.6 / 5.2$ & $2.8 / 3.5$ & Val & $505 / 515$ & $580 / 600$ \\
\hline Dronpa & 2IE2 & 69 & 5.0 & $2.8 / 4.1$ & Ala & $503 / 518$ & - \\
\hline
\end{tabular}

Fluorescence Spectra of Green Dendra2. Figure 7A shows excitation and emission spectra of the neutral green chromophore for different $\mathrm{pH}$ values. The excitation spectra were recorded with the emission monochromator set to $450 \mathrm{~nm}$; the emission spectra were collected with $375 \mathrm{~nm}$ excitation. To display the different spectra within the same plot and to compare their relative intensities, the excitation and emission spectra were adjusted for slight differences in protein concentration, as judged by the protein absorption at $280 \mathrm{~nm}$. Subsequently, the intensities of the excitation maximum at $378 \mathrm{~nm}$ and the emission maximum at $454 \mathrm{~nm}$ (at pH 4) were normalized to 1. The remaining spectra were scaled so as to maintain the relative intensities.

In its $\mathrm{pH}$ variation, the amplitude of the excitation band scales with that of the corresponding absorption band $(\mathrm{p} K=7.1)$. The $280 \mathrm{~nm}$ band is less pronounced in the excitation than in the absorption spectrum, indicating that the probability of transferring the excitation of aromatic amino acids to the chromophore is markedly below 1. Excitation of the neutral chromophore at $375 \mathrm{~nm}$ produces weak blue fluorescence at $454 \mathrm{~nm}$, the intensity of which also varies with $\mathrm{pH}$ according to $\mathrm{pK} 7.1$ and, consequently, with the population of neutral chromophore (Figure 7A). Upon $375 \mathrm{~nm}$ excitation, fluorescence emission of the green anionic chromophore at $504.5 \mathrm{~nm}$ is also observed. At $\mathrm{pH}<5$, the population of anionic species is very low (Figure 6B), and therefore, we attribute this emission to a process involving excited-state proton transfer (ESPT) (50,55-57). With increasing $\mathrm{pH}$, emission by the anionic chromophore gets larger, which cannot be explained by ESPT anymore, as the fraction of neutral chromophores decreases. Instead, we record direct excitation of the anionic species even at $375 \mathrm{~nm}$; its excitation band extends to wavelengths as low as $350 \mathrm{~nm}$ (Figure 7B). We emphasize here that the overall intensities of the fluorescence spectra in Figure 7A are $\sim 100$-fold lower than those in Figure 7B. Excitation $\left(\lambda_{\operatorname{det}}=520 \mathrm{~nm}\right)$ and emission $\left(\lambda_{\text {exc }}=480 \mathrm{~nm}\right)$ spectra of the anionic green chromophore are shown in Figure 7B for selected $\mathrm{pH}$ values. The $\mathrm{pH}$ dependencies of both fluorescence excitation and emission intensities are also well modeled with $\mathrm{p} K=7.1$ and thus scale directly with the fraction of anionic chromophores.

At $\mathrm{pH}$ 7, their maxima are located at 492.6 and $504.5 \mathrm{~nm}$, respectively. Both bands show vibronic structure, with side bands centered on 460.8 and at $542.0 \mathrm{~nm}$. This substructure of both the excitation and emission band indicates a coupling of the chromophore to a vibrational mode with a frequency of $1400 \pm$ $50 \mathrm{~cm}^{-1}$. Völker and co-workers have reported frequencies of

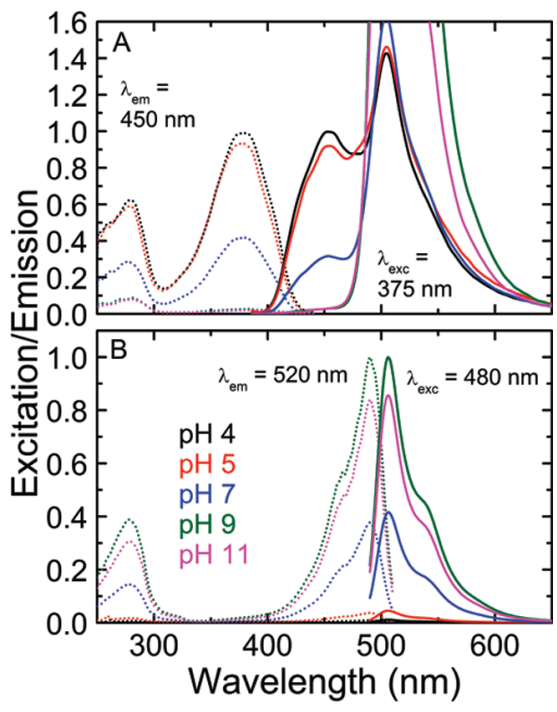

FIGURE 7: Excitation (dotted lines) and emission (solid lines) spectra of green Dendra2 at different $\mathrm{pH}$ values. (A) Neutral chromophore. (B) Anionic chromophore.

220,770 , and $1508 \mathrm{~cm}^{-1}$ from their spectral hole-burning investigation (58), with the latter two frequencies corresponding to local modes of the chromophore coupled to the electronic transition. Indeed, in the resonance Raman spectrum of avGFP, the strongest signal is at $\sim 1560 \mathrm{~cm}^{-1}$ (59), which has been assigned to a normal mode delocalized over the imidazolinone ring and the exocyclic double bond by isotope labeling studies (60).

Photoconversion of Dendra2. Green Dendra2 can be efficiently converted to red Dendra2 by illumination with $405 \mathrm{~nm}$ light, as shown in the time sequence of spectra in Figure 8A. To test the hypothesis that photoconversion starts from the neutral green chromophore $(27,34)$, green Dendra2 at $\mathrm{pH} 7$ was illuminated for $5 \mathrm{~min}$ with light of different wavelengths (300$500 \mathrm{~nm}, 10 \mathrm{~nm}$ steps). The achieved increase in fluorescence intensity of the anionic red species $\left(\lambda_{\mathrm{exc}}=550 \mathrm{~nm}, \lambda_{\mathrm{det}}=\right.$ $625 \mathrm{~nm}$ ) was adjusted for variations in the lamp intensity. In accordance with the findings on EosFP (27) and Kaede (29), the resulting action spectrum, which describes the efficiency of Dendra2 photoconversion, indeed tracks the absorption band of the neutral green species (Figure 8A).

We also verified that the kinetics of photoconversion in Dendra2 is proportional to the concentration of neutral green chromophores. We illuminated $1 \mu \mathrm{M}$ solutions of green Dendra2 

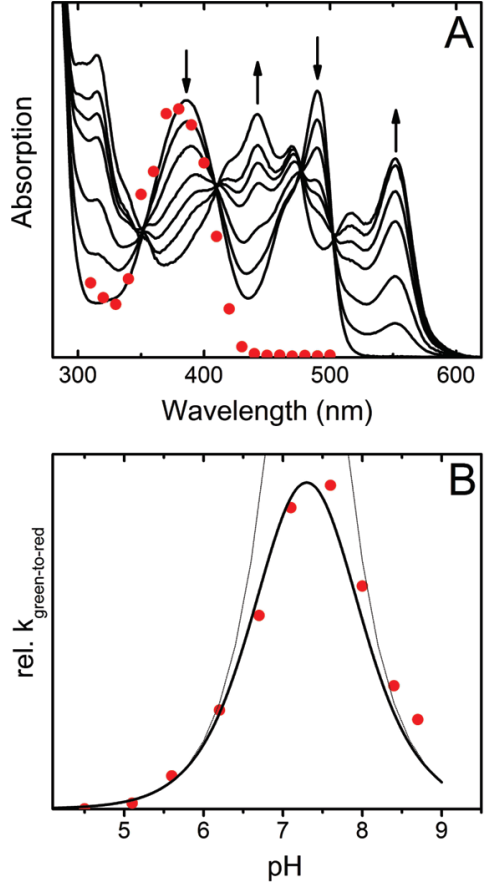

Figure 8: (A) Absorption spectra of Dendra2 measured during photoconversion at $\mathrm{pH} 7$ with $405 \mathrm{~nm}$ light. Arrows indicate changes with time. Red dots: action spectrum. (B) $\mathrm{pH}$ dependence of photoconversion (symbols). The expected $\mathrm{pH}$ dependence (thick line) is calculated from the probability for having a neutral green chromophore weighted by the probability to yield a red anionic chromophore (thin lines).

at different $\mathrm{pH}$ values with $405 \mathrm{~nm}$ light at $1 \mathrm{~mW} / \mathrm{cm}^{2}$ for $300 \mathrm{~s}$. Before and after illumination, we measured the fluorescence intensity at $625 \mathrm{~nm}$. The excitation wavelength was set to $550 \mathrm{~nm}$ to only excite the anionic red species (see below). In Figure 8B, the relative increase of the fluorescence intensity is plotted as a function of $\mathrm{pH}$. The solid line indicates the expected fluorescence increase if we assume that only neutral green Dendra2 photoconverts and if we account for the probability to obtain the red anionic species at the selected $\mathrm{pH}$ (see below). The good agreement between data and model curve confirms that the rate of photoconversion is indeed proportional to the concentration of neutral green Dendra2.

Absorption Spectra of Red Dendra2. The absorption spectra of red Dendra2 display two sets of bands (Figure 6C), the fractional areas of which change with $\mathrm{pH}$ in accordance with a single-site protonation, with $\mathrm{p} K=7.5$ (Figure $6 \mathrm{D}$ ), slightly above the $\mathrm{p} K$ of 7.1 characterizing the green chromophore. As for the $p$-HBI chromophore of the green species, these bands are also associated with the neutral (A) and the anionic (B) red chromophores. The anionic species peaks at $555.6 \mathrm{~nm}$ (Table 2). A pronounced vibronic side band is visible at $515.5 \mathrm{~nm}$; a second one is seen at $478.5 \mathrm{~nm}$. Compared with EosFP, the anionic form of which absorbs at $571 \mathrm{~nm}$, the red form of Dendra2 is markedly shifted to the blue by $15 \mathrm{~nm}$. The shift is thus similar to that of the green species $(13 \mathrm{~nm})$ and, as discussed above, may be related to the missing interaction of the charged guanidino group of Arg66 with the imidazolinone carbonyl. A weak shoulder toward the red side of the $\mathrm{B}$ band is also visible and can be modeled with a band at $586 \mathrm{~nm}$, which may represent a "super-red" species, similar to the one found in DsRed $(61,62)$. As for DsRed, the population of this species can be enhanced by intense laser illumination (not shown).
For the neutral red chromophore, the maximum absorbance is located at $440.5 \mathrm{~nm}$. This peak, however, is a vibronic band of the 0-0 transition located at $471.7 \mathrm{~nm}$ (see below). Still higher vibronic bands are visible toward the blue side, at 414.9 and $393.7 \mathrm{~nm}$. Less pronounced features between 300 and $380 \mathrm{~nm}$ are associated with higher electronic transitions of both the neutral and anionic red chromophore species.

At $\mathrm{pH}$ 12, base-denatured Dendra2 has a very broad absorption band with a maximum at $499 \mathrm{~nm}$; minor bands are visible at 330, 347, and $364 \mathrm{~nm}$ (dotted line in Figure 6B). Under identical conditions, the absorption spectrum of red EosFP also displays a broad band, with a maximum at $494 \mathrm{~nm}$. By contrast, basedenatured red FPs with a 2-imino-5-(4-hydroxybenzylidene) imidazolinone chromophore such as eqFP611 (63) and DsRed (64) display an absorption band at $450-460 \mathrm{~nm}$, similar to avGFP (53). Apparently, the acylimine of the red chromophore is unstable under these conditions, as was also reported for the chromoprotein RTMS5 at extreme $\mathrm{pH}$ values (65). As the red chromophores of Dendra2 and EosFP absorb $50 \mathrm{~nm}$ further to the red, the alkenylene extension of the $p$-HBI chromophore is most likely still in place at $\mathrm{pH} 12$.

The band of the acid-denatured red chromophore peaks at 382 $\mathrm{nm}$ and looks identical to that of the green chromophore (compare the dashed lines in panels A and B of Figure 6), suggesting a destruction of the alkenylene extension under acidic conditions.

Fluorescence Properties of red Dendra2. Fluorescence excitation and emission spectra of red Dendra2 are compiled in Figure 9 for $\mathrm{pH} 4,6,8$, and 10. Excitation spectra were measured with the emission wavelength set close to the emission peaks of the neutral $\left(\lambda_{\text {det }}=520 \mathrm{~nm}\right.$, black dotted lines) and anionic red chromophores $\left(\lambda_{\text {det }}=570 \mathrm{~nm}\right.$, red dotted lines). Emission spectra were taken with excitation near the absorption maxima at $\lambda_{\text {exc }}=440 \mathrm{~nm}$ and $\lambda_{\text {exc }}=550 \mathrm{~nm}$ (solid black and red lines). The spectra were adjusted for slight differences in protein concentration as determined from the absorption at $280 \mathrm{~nm}$.

At pH 4, only the neutral chromophore species contributes to the absorption spectrum (Figure 6C). Hence, direct excitation of the anionic chromophore $\left(\lambda_{\mathrm{exc}}=550 \mathrm{~nm}\right)$ yields no fluorescence emission because this species is absent at $\mathrm{pH} 4$. The excitation spectrum of the neutral chromophore in Figure 9A, measured with $\lambda_{\text {det }}=520 \mathrm{~nm}$, consists of a series of comparatively wellresolved bands that we assign to the $0-0$ transition at $471.7 \mathrm{~nm}$ and a progression of vibronic bands, with the largest excitation peak at $440.5 \mathrm{~nm}$, another one at $414.9 \mathrm{~nm}$, and a weak shoulder at $393.7 \mathrm{~nm}$. The energy gap corresponding to the wavelength differences between the bands indicates that an $\sim 1400 \mathrm{~cm}^{-1}$ vibrational mode of the chromophore is strongly coupled to the electronic transition, similarly to the observation made in the green state. A remarkably strong excitation band associated with a transition into a higher electronic state is present at $318 \mathrm{~nm}$. The excitation spectra measured with $\lambda_{\operatorname{det}}=480,520$, and $570 \mathrm{~nm}$ are identical except for a scale factor accounting for the different amplitudes of the emission spectrum, implying that the emission peaks at 488.8, 516.8, and $561.8 \mathrm{~nm}$ (Figure 9A) belong to the same electronic transition. The excitation spectra track the absorption spectrum between 300 and $560 \mathrm{~nm}$; the $280 \mathrm{~nm}$ band is lower in the excitation spectrum, however, implying that only a fraction of the excitation of aromatic residues is transferred to the chromophore.

The emission spectrum associated with the neutral red chromophore looks like the mirror image of the excitation spectrum, 


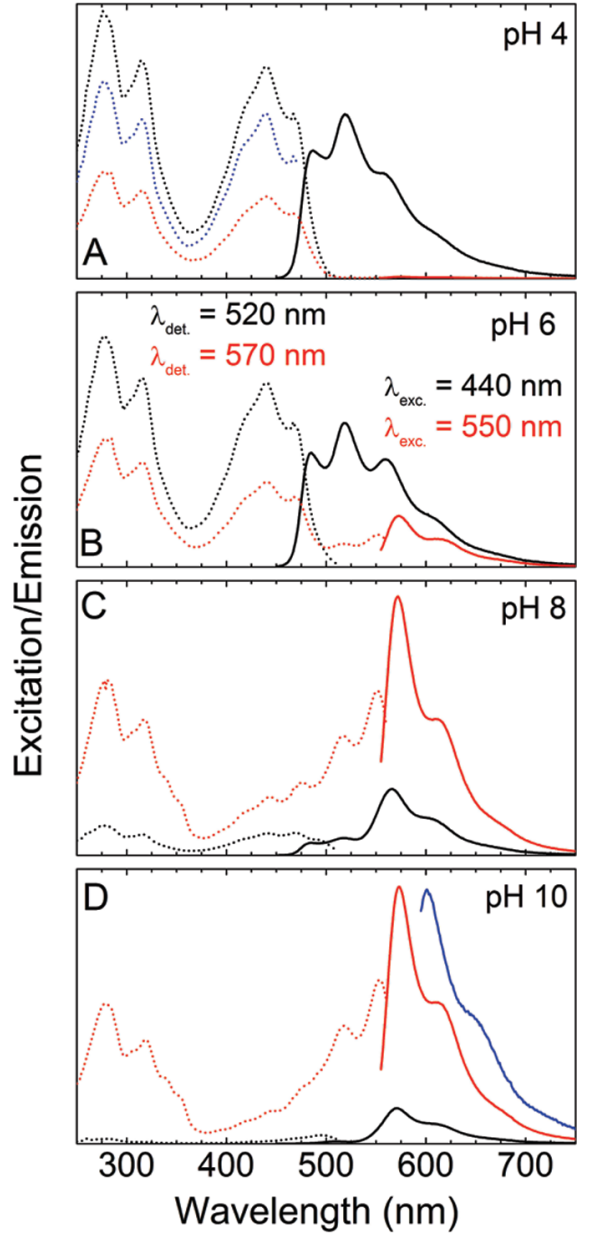

FIgURE 9: Excitation (dotted lines) and emission (solid lines) spectra of red Dendra2 at (A) $\mathrm{pH} 4$, (B) $\mathrm{pH} 6,(\mathrm{C}) \mathrm{pH} 8$, and (D) $\mathrm{pH} 10$. Emission was excited at $440 \mathrm{~nm}$ (black), $550 \mathrm{~nm}$ (red), and $590 \mathrm{~nm}$ (blue). Excitation spectra were recorded with detection at $480 \mathrm{~nm}$ (blue), $520 \mathrm{~nm}$ (black), and $570 \mathrm{~nm}$ (red).

and the energy separation of the peaks corresponds to a similar vibronic excitation of $1400 \mathrm{~cm}^{-1}$ as in the excitation spectra. $\mathrm{He}$ et al. have synthesized two compounds, HBMPI and HBMPDI, designed to model the chromophore of DsRed (66). Compared to the green model chromophore, they contain one and two additional conjugated double bonds, respectively. Their Raman spectra show that the band assigned to the mode localized over the imidazolinone ring and the exocyclic $\mathrm{C}=\mathrm{C}$ bond shifts slightly upon extending the conjugated $\pi$-system. Our spectral resolution is, however, not sufficient to resolve this difference in the vibrational modes of the green and red chromophores.

We determined the quantum yield $(\mathrm{QY})$ of neutral red Dendra2 at $\mathrm{pH} 5$ as 0.45 , which is somewhat lower than the value obtained for the anionic chromophore at $\mathrm{pH} 9(\mathrm{QY}=$ 0.61). Unlike neutral Dendra2, the neutral form of red EosFP shows neither appreciable direct fluorescence emission nor emission by the anionic chromophore via ESPT (27). Apparently, nonradiative deexcitation pathways are preferred in EosFP, which typically involve rotation of the chromophore around its exocyclic bonds, so that fast radiationless decay can proceed upon crossing of the $\mathrm{S}_{0}$ and $\mathrm{S}_{1}$ surfaces (67). On the basis of the structure, we may speculate that the tight salt-bridge interaction between Arg66 and Glu211 in Dendra2 (Figure 4A) creates a more rigid environment that maintains the neutral, highly fluorescent red chromophore in a coplanar conformation, which is essential for a high fluorescence quantum yield.

The very low QY of the neutral green chromophore still calls for an explanation. A high fluorescence QY requires that the two rings of the $p$-HBI chromophore are tightly fixed in a coplanar conformation by the surrounding residues and bound water molecules $(68,69)$. As a matter of fact, the isolated chromophore in solution does not show any fluorescence because it rotates around its exocyclic bonds and undergoes fast radiationless decay by internal conversion upon reaching an avoided crossing of the $\mathrm{S}_{0}$ and $\mathrm{S}_{1}$ surfaces $(67,70)$. A direct coupling between chromophore planarity and QY was reported by Shu et al. for DsRed variants (71). The crystal structure reported here, which was determined at $\mathrm{pH} 8.5$, corresponds to the anionic species and, therefore, does not allow us to assess the structure of the neutral species. Presumably, the green neutral chromophore is held in a nonplanar configuration because of restrictions due to the backbone linkage, which are removed in the red species. It is also feasible that the neutral green chromophore experiences increased torsional mobility so that nonradiative deexcitation is enhanced $(70,72)$.

In the physiological range between $\mathrm{pH} 6$ and 8 , both the neutral and anionic species of the red chromophore contribute to the fluorescence spectra (Figure 9B,C). Around $\mathrm{pH} \mathrm{10,} \mathrm{the}$ chromophore exists only in its anionic form ( $\mathrm{p} K=7.5$, Figure 6D). Its excitation spectrum $\left(\lambda_{\mathrm{det}}=570 \mathrm{~nm}\right)$ reveals the 0-0 transition at $555.6 \mathrm{~nm}$, a pronounced vibronic side band at $515.5 \mathrm{~nm}$, and a less resolved band at $478.5 \mathrm{~nm}$, indicating again a coupling to a vibrational mode of $\sim 1400 \mathrm{~cm}^{-1}$. Additional bands associated with higher electronic transitions are found at 318, 341, and $355 \mathrm{~nm}$ (Figure 9D). The emission spectrum measured with $550 \mathrm{~nm}$ excitation has a dominant band at $570.5 \mathrm{~nm}$, with shoulders at 619.2 and $675.7 \mathrm{~nm}$.

In the absorption spectra of red Dendra2, we noticed a broad tail toward the red side of the spectrum, which may indicate an additional band at $586 \mathrm{~nm}$ (Figure 8). To further investigate this feature, we collected an emission spectrum with excitation on the red edge of this band. This spectrum, shown in Figure 9D in blue, has its maximum at $600 \mathrm{~nm}$. This observation further supports the notion that a "super-red" species $(61,62)$ exists in Dendra2.

\section{DISCUSSION AND CONCLUSION}

The X-ray structure of Dendra2 reveals a network of salt bridges and hydrogen bonds beneath the chromophore, which is typically found in anthozoan FPs. Compared to EosFP (32), Dendra2 shows a pronounced structural difference in this network that involves amino acid residue Arg66 and the water molecule W4. Arg66 does not form a hydrogen bond with the imidazolinone ring of the chromophore and, thus, does not contribute to negative charge density stabilization on the ring. We propose that the absorption and emission bands of Dendra2 are blue shifted from EosFP as a result of this lacking interaction. The Thr69Ala mutation indeed renders Dendra2 EosFP-like and removes the blue shift (Table 3).

Our suggestion is further supported by a comparison with other FPs listed in Table 3. The Dendra2-like orientation of the Arg66 side chain is found in mTFP1 (49), amFP486 (47), mKO (48), zFP538 (46), and cmFP512 (73), whereas the EosFP-like orientation of the Arg66 side chain is shared by Kaede (35), mKikGR (30), and Dronpa (74). In these latter FPs, the amino acid at position 69 is either an alanine or a valine, which cannot establish a hydrogen-bonding interaction with Arg66 (Figure 5). 
A comparison of the excitation and emission maxima of these proteins reveals that the bands of the Dendra2-like FPs are blue shifted by at least $10 \mathrm{~nm}$ with respect to the EosFP-type ones (Table 3), with the exception of cmFP512 (73). This FP, however, has an alanine instead of a serine at position 142, which compensates the blue shift (vide infra). This claim is supported by the blue-shifted bands in cmFP512 mutant Ala142Ser (73).

An additional blue shift can be achieved by efficient charge stabilization of the phenolate chromophore, i.e., a low $\mathrm{p} K$ value. As electronic excitation of the chromophore generates a shift of electron density from the hydroxyphenyl moiety toward the imidazolinone heterocycle (75-77), an efficient solvation of the phenolate destabilizes the excited state with respect to the ground state. Other Dendra2-like FPs have significantly lower $\mathrm{p} K$ values of the green chromophore than Dendra2 (Table 3) and a larger blue shift of the absorption/emission maxima (Table 3). In mTFP1, additional stabilization is achieved by His 159 (His163 in mTFP1 numbering, Met159 in Dendra2), which is in hydrogen-bonding distance to the hydroxyphenyl moiety $(2.6 \AA)$. In $\mathrm{mKO}$, the distance between Ser142 and the hydroxyphenyl moiety is decreased with respect to Dendra2, leading to a stronger hydrogen bond and thus a better stabilization. The Ala142Ser mutant of cmFP512 shows the smallest blue shift with respect to Dendra2, although the anionic chromophore is strongly stabilized by Ser142, Lys159, and a water molecule (73). However, the interaction between Arg91 and the imidazolinone heterocycle may be stronger than in the other FPs discussed here, as inferred from the distances between Arg91$\mathrm{N} \eta_{1} / \operatorname{Arg} 91-\mathrm{N} \eta_{2}$ and the imidazolinone oxygen (Table 3), leading to a more efficient excited-state stabilization and thus to a reduced blue shift. To summarize, the results presented here on Dendra2 and the structural comparison with other FPs strongly suggest that a shift of the green chromophore to the cyan and blue region (and a shift of the red chromophore toward the orange region) can be effected in two ways: (1) by enhancing the charge stabilization on the phenolate oxygen of the anionic chromophore and (2) by reducing charge stabilization of the carbonyl oxygen of the heterocycle.

Remington and co-workers investigated the network of salt bridges and hydrogen bonds beneath the chromophore in the cyan amFP486 and gave an alternative explanation of its blue shift (47). They suggested that the His 193 side chain carries a positive charge so as to maintain overall charge neutrality of the quadrupole network and argued that the imidazolium side chain stabilizes the charge on the hydroxyphenyl ring of the chromophore. The reduced extent of charge delocalization upon excitation should result in blue-shifted absorption and emission spectra of amFP486. This explanation may be challenged by recent results from another cyan FP, dsFP483 (78), which has strongly blue-shifted spectra but a (neutral) threonine instead of a histidine residue at the corresponding position.

Green-to-red photoconversion starts from the neutral green species, as is evident from the $\mathrm{pH}$ dependencies of the photoconversion rates and action spectra of EosFP (27), Kaede (29), and Dendra2 (Figure 8). Because of the higher $\mathrm{p} K$ of the latter protein, the concentration of the neutral Dendra2 species is 20fold higher under physiological conditions as compared with EosFP, which enhances the green-to-red photoconversion yield by the same factor. In a confocal microscope, high power densities are available so that photoconversion with blue light $(488 \mathrm{~nm})$ is easily observed (36). Photoconversion of a bulk sample in a cuvette is, however, much less efficient due to illumination with unfocused light. We note that EosFP can also be photoconverted by $488 \mathrm{~nm}$ light in a confocal microscope, as we had shown earlier in Figure 6A in ref 27, where a few single molecules change their emission wavelengths from green to red while the surface is scanned with $488 \mathrm{~nm}$ light. In Dendra2, the red chromophore formed after conversion fluoresces efficiently in both its neutral and anionic forms. In fluorescence imaging applications, both green and red Dendra2 species can be excited efficiently between 450 and $500 \mathrm{~nm}$, e.g., with 473 or $488 \mathrm{~nm}$ laser lines, and selective excitation of the red species is achieved by excitation above $\sim 510 \mathrm{~nm}$, e.g., with $532 \mathrm{~nm}$ laser lines.

Our structural and spectroscopic investigations on Dendra2 have underscored the similarities among FPs of the green-to-red photoconverting class. Remarkably, the altered optical properties of Dendra2 with respect to its close cousins EosFP and Kaede can be traced to a local structural change near the chromophore. This analysis further contributes to our understanding of structure-dynamics-function relationships in FPs, which is required for a rational engineering of FPs with advanced properties as fluorescence markers.

\section{SUPPORTING INFORMATION AVAILABLE}

Amino acid sequence alignment and UV/vis absorption spectra of green Dendra2. This material is available free of charge via the Internet at http://pubs.acs.org.

\section{REFERENCES}

1. Shaner, N. C., Patterson, G. H., and Davidson, M. W. (2007) Advances in fluorescent protein technology. J. Cell Sci. 120, 4247-4260.

2. Giepmans, B. N., Adams, S. R., Ellisman, M. H., and Tsien, R. Y. (2006) The fluorescent toolbox for assessing protein location and function. Science 312, 217-224.

3. Lippincott-Schwartz, J., Snapp, E., and Kenworthy, A. (2001) Studying protein dynamics in living cells. Nat. Rev. Mol. Cell. Biol. 2, $444-456$.

4. Shcherbo, D., Merzlyak, E. M., Chepurnykh, T. V., Fradkov, A. F., Ermakova, G. V., Solovieva, E. A., Lukyanov, K. A., Bogdanova, E. A., Zaraisky, A. G., Lukyanov, S., and Chudakov, D. M. (2007) Bright far-red fluorescent protein for whole-body imaging. Nat. Methods 4, 741-746.

5. Shimomura, O., Johnson, F. H., and Saiga, Y. (1962) Extraction, purification and properties of aequorin, a bioluminescent protein from the luminous hydromedusan, Aequorea. J. Cell. Comp. Physiol. 59, 223-239.

6. Chalfie, M., Tu, Y., Euskirchen, G., Ward, W. W., and Prasher, D. C. (1994) Green fluorescent protein as a marker for gene expression. Science 263, 802-805.

7. Prasher, D. C., Eckenrode, V. K., Ward, W. W., Prendergast, F. G., and Cormier, M. J. (1992) Primary structure of the Aequorea victoria green-fluorescent protein. Gene 111, 229-233.

8. Nienhaus, G. U. (2008) The green fluorescent protein: a key tool to study chemical processes in living cells. Angew. Chem., Int. Ed. 47, 8992-8994. Angew. Chem. 120, 4398-4402.

9. Wiedenmann, J. (1997) Patent DE 19718 640, Deutsches Patent- und Markenamt.

10. Matz, M. V., Fradkov, A. F., Labas, Y. A., Savitsky, A. P., Zaraisky, A. G., Markelov, M. L., and Lukyanov, S. A. (1999) Fluorescent proteins from nonbioluminescent Anthozoa species. Nat. Biotechnol. 17, 969-973.

11. Wiedenmann, J., Ivanchenko, S., Oswald, F., and Nienhaus, G. U. (2004) Identification of GFP-like proteins in nonbioluminescent, azooxanthellate Anthozoa opens new perspectives for bioprospecting. Mar. Biotechnol. (New York) 6, 270-277.

12. Nienhaus, G. U., Nienhaus, K., Hölzle, A., Ivanchenko, S., Renzi, F., Oswald, F., Wolff, M., Schmitt, F., Röcker, C., Vallone, B., Weidemann, W., Heilker, R., Nar, H., and Wiedenmann, J. (2006) Photoconvertible fluorescent protein EosFP-Biophysical properties and cell biology applications. Photochem. Photobiol. 82, 351-358.

13. Nienhaus, G. U., and Wiedenmann, J. (2009) Structure, dynamics and optical properties of fluorescent proteins: perspectives for marker development. ChemPhysChem DOI: 10.1002/cphc.200800839. 
14. Yang, F., Moss, L. G., and Phillips, G. N.Jr. (1996) The molecular structure of green fluorescent protein. Nat. Biotechnol. 14, 1246-1251.

15. Ormö, M., Cubitt, A. B., Kallio, K., Gross, L. A., Tsien, R. Y., and Remington, S. J. (1996) Crystal structure of the Aequorea victoria green fluorescent protein. Science 273, 1392-1395.

16. Tsien, R. Y. (1998) The green fluorescent protein. Annu. Rev. Biochem. 67, 509-544.

17. Cubitt, A. B., Heim, R., Adams, S. R., Boyd, A. E., Gross, L. A., and Tsien, R. Y. (1995) Understanding, improving and using green fluorescent proteins. Trends Biochem. Sci. 20, 448-455.

18. Yarbrough, D., Wachter, R. M., Kallio, K., Matz, M. V., and Remington, S. J. (2001) Refined crystal structure of DsRed, a red fluorescent protein from coral, at $2.0-\AA$ A resolution. Proc. Natl. Acad. Sci. U.S.A. 98, 462-467.

19. Wall, M. A., Socolich, M., and Ranganathan, R. (2000) The structural basis for red fluorescence in the tetrameric GFP homolog DsRed. Nat. Struct. Biol. 7, 1133-1138.

20. Petersen, J., Wilmann, P. G., Beddoe, T., Oakley, A. J., Devenish, R. J., Prescott, M., and Rossjohn, J. (2003) The 2.0-A crystal structure of eqFP611, a far red fluorescent protein from the sea anemone Entacmaea quadricolor. J. Biol. Chem. 278, 44626-44631.

21. Lippincott-Schwartz, J., and Patterson, G. H. (2003) Development and use of fluorescent protein markers in living cells. Science 300, $87-91$.

22. Ivanchenko, S., Glaschick, S., Röcker, C., Oswald, F., Wiedenmann, J., and Nienhaus, G. U. (2007) Two-photon excitation and photoconversion of EosFP in dual-color 4Pi confocal microscopy. Biophys. J. 92, 4451-4457.

23. Betzig, E., Patterson, G. H., Sougrat, R., Lindwasser, O. W., Olenych, S., Bonifacino, J. S., Davidson, M. W., Lippincott-Schwartz, J., and Hess, H. F. (2006) Imaging intracellular fluorescent proteins at nanometer resolution. Science 313, 1642-1645.

24. Hell, S. W. (2007) Far-field optical nanoscopy. Science 316, 1153-1158.

25. Hess, S. T., Girirajan, T. P., and Mason, M. D. (2006) Ultra-high resolution imaging by fluorescence photoactivation localization microscopy. Biophys. J. 91, 4258-4272.

26. Hell, S. W. (2009) Microscopy and its focal switch. Nat. Methods 6, 24-32.

27. Wiedenmann, J., Ivanchenko, S., Oswald, F., Schmitt, F., Röcker, C., Salih, A., Spindler, K. D., and Nienhaus, G. U. (2004) EosFP, a fluorescent marker protein with UV-inducible green-to-red fluorescence conversion. Proc. Natl. Acad. Sci. U.S.A. 101, 15905-15910.

28. Oswald, F., Schmitt, F., Leutenegger, A., Ivanchenko, S., D'Angelo, C., Salih, A., Maslakova, S., Bulina, M., Schirmbeck, R., Nienhaus, G. U., Matz, M. V., and Wiedenmann, J. (2007) Contributions of host and symbiont pigments to the coloration of reef corals. FEBS J. 274, $1102-1109$

29. Ando, R., Hama, H., Yamamoto-Hino, M., Mizuno, H.and Miyawaki, A. (2002) An optical marker based on the UV-induced green-to-red photoconversion of a fluorescent protein. Proc. Natl. Acad. Sci. U.S.A. 99, 12651-12656.

30. Tsutsui, H., Karasawa, S., Shimizu, H., Nukina, N., and Miyawaki, A. (2005) Semi-rational engineering of a coral fluorescent protein into an efficient highlighter. EMBO Rep. 6, 233-238.

31. Labas, Y. A., Gurskaya, N. G., Yanushevich, Y. G., Fradkov, A. F., Lukyanov, K. A., Lukyanov, S. A., and Matz, M. V. (2002) Diversity and evolution of the green fluorescent protein family. Proc. Natl. Acad. Sci. U.S.A. 99, 4256-4261.

32. Nienhaus, K., Nienhaus, G. U., Wiedenmann, J., and Nar, H. (2005) Structural basis for green-to-red photoconversion of fluorescent protein EosFP. Proc. Natl. Acad. Sci. U.S.A. 102, 9156-9159.

33. Adam, V., Lelimousin, M., Boehme, S., Desfonds, G., Nienhaus, K., Field, M. J., Wiedenmann, J., McSweeney, S., Nienhaus, G. U., and Bourgeois, D. (2008) Structural characterization of IrisFP, an optical highlighter undergoing multiple photo-induced transformations. Proc. Natl. Acad. Sci. U.S.A. 105, 18343-18348.

34. Mizuno, H., Mal, T. K., Tong, K. I., Ando, R., Furuta, T., Ikura, M., and Miyawaki, A. (2003) Photo-induced peptide cleavage in the green-to-red conversion of a fluorescent protein. Mol. Cell 12, $1051-1058$

35. Hayashi, I., Mizuno, H., Tong, K. I., Furuta, T., Tanaka, F., Yoshimura, M., Miyawaki, A., and Ikura, M. (2007) Crystallographic evidence for water-assisted photo-induced peptide cleavage in the stony coral fluorescent protein Kaede. J. Mol. Biol. 372, 918-926.

36. Gurskaya, N. G., Verkhusha, V. V., Shcheglov, A. S., Staroverov, D. B., Chepurnykh, T. V., Fradkov, A. F., Lukyanov, S., and Lukyanov, K. A. (2006) Engineering of a monomeric green-to-red photoactivatable fluorescent protein induced by blue light. Nat. Biotechnol. 24, $461-465$.
37. Berglund, G. I., Carlsson, G. H., Smith, A. T., Szoke, H., Henriksen, A., and Hajdu, J. (2002) The catalytic pathway of horseradish peroxidase at high resolution. Nature 417, 463-468.

38. Kabsch, W. (1993) Automatic processing of rotation diffraction data from crystals of initially unknown symmetry and cell constants. J. Appl. Crystallogr. 26, 795-800.

39. McCoy, A. J., Grosse-Kunstleve, R. W., Adams, P. D., Winn, M. D., Storoni, L. C., and Read, R. J. (2007) Phaser crystallographic software. Acta Crystallogr. D 40, 658-674.

40. Murshudov, G. N., Vagin, A. A., and Dodson, E. J. (1997) Refinement of macromolecular structures by the maximum-likelihood method. Acta Crystallogr. D 53, 240-255.

41. Emsley, P., and Kowtan, K. (2004) COOT version 0.026 model building and molecular graphics system. Acta Crystallogr. D 70, 2126-2132.

42. Bailey, S. (1994) The CCP4 suite: programs for protein crystallography. Acta Crystallogr. D 50, 760-763.

43. Kleywegt, G. J., and Jones, T. A. (1998) Databases in protein crystallography. Acta Crystallogr. D 54, 1119-1131.

44. Wiedenmann, J., Vallone, B., Renzi, F., Nienhaus, K., Ivanchenko, S., Röcker, C., and Nienhaus, G. U. (2005) Red fluorescent protein eqFP611 and its genetically engineered dimeric variants. J. Biomed. Opt. 10, 14003.

45. Nienhaus, K., Vallone, B., Renzi, F., Wiedenmann, J., and Nienhaus, G. U. (2003) Crystallization and preliminary X-ray diffraction analysis of the red fluorescent protein eqFP611. Acta Crystallogr. D 59, 1253-1255.

46. Remington, S. J., Wachter, R. M., Yarbrough, D. K., Branchaud, B., Anderson, D. C., Kallio, K., and Lukyanov, K. A. (2005) zFP538, a yellow-fluorescent protein from Zoanthus, contains a novel three-ring chromophore. Biochemistry 44, 202-212.

47. Henderson, J. N., and Remington, S. J. (2005) Crystal structures and mutational analysis of amFP486, a cyan fluorescent protein from Anemonia majano. Proc. Natl. Acad. Sci. U.S.A. 102, 12712-12717.

48. Kikuchi, A., Fukumura, E., Karasawa, S., Mizuno, H., Miyawaki, A., and Shiro, Y. (2008) Structural characterization of a thiazolinecontaining chromophore in an orange fluorescent protein, monomeric Kusabira Orange. Biochemistry 47, 11573-11580.

49. Ai, H. W., Olenych, S. G., Wong, P., Davidson, M. W., and Campbell, R. E. (2008) Hue-shifted monomeric variants of Clavularia cyan fluorescent protein: identification of the molecular determinants of color and applications in fluorescence imaging. BMC Biol. 6, 13 .

50. Chattoraj, M., King, B. A., Bublitz, G. U., and Boxer, S. G. (1996) Ultra-fast excited state dynamics in green fluorescent protein: multiple states and proton transfer. Proc. Natl. Acad. Sci. U.S.A. 93, 8362-8367.

51. Elsliger, M. A., Wachter, R. M., Hanson, G. T., Kallio, K., and Remington, S. J. (1999) Structural and spectral response of green fluorescent protein variants to changes in $\mathrm{pH}$. Biochemistry 38, 5296-5301.

52. Voityuk, A. A., Michel-Beyerle, M. E., and Rösch, N. (1998) Quantum chemical modeling of structure and absorption spectra of the chromophore in green fluorescent proteins. Chem. Phys. 231, 13-25.

53. Ward, W. W., and Bokman, S. H. (1982) Reversible denaturation of Aequorea green-fluorescent protein: physical separation and characterization of the renatured protein. Biochemistry 21, 4535-4540.

54. Webber, N. M., and Meech, S. R. (2007) Electronic spectroscopy and solvatochromism in the chromophore of GFP and the Y66F mutant. Photochem. Photobiol. Sci. 6, 976-981.

55. Lossau, H., Kummer, A., Heinecke, R., Pollinger-Dammer, F., Kompa, C., Bieser, G., Jonsson, T., Silva, C. M., Yang, M. M., Youvan, D. C., and Michel-Beyerle, M. E. (1996) Time-resolved spectroscopy of wild-type and mutant green fluorescent proteins reveals excited state deprotonation consistent with fluorophore-protein interactions. Chem. Phys. 213, 1-16.

56. Lill, M. A., and Helms, V. (2002) Proton shuttle in green fluorescent protein studied by dynamic simulations. Proc. Natl. Acad. Sci. U.S.A. 99, 2778-2781.

57. Stoner-Ma, D., Jaye, A. A., Matousek, P., Towrie, M., Meech, S. R., and Tonge, P. J. (2005) Observation of excited-state proton transfer in green fluorescent protein using ultrafast vibrational spectroscopy. J. Am. Chem. Soc. 127, 2864-2865.

58. Creemers, T. M. H., Lock, A. J., Subramaniam, V., Jovin, T. M., and Völker, S. (1999) Three photoconvertible forms of green fluorescent protein identified by spectral hole-burning. Nat. Struct. Biol. 6, 557-560.

59. Schellenberg, P., Johnson, E., Esposito, A. P., Reid, P. J., and Parson, W. W. (2001) Resonance Raman scattering by the green fluorescent protein and an analogue of its chromophore. J. Phys. Chem. B 105, 5316-5322. 
60. He, X., Bell, A. F., and Tonge, P. J. (2002) Isotopic labeling and normal-mode analysis of a model green fluorescent protein chromophore. J. Phys. Chem. B 106, 6056-6066.

61. Cotlet, M., Hofkens, J., Habuchi, S., Dirix, G., Van Guyse, M., Michiels, J., Vanderleyden, J., and De Schryver, F. C. (2001) Identification of different emitting species in the red fluorescent protein DsRed by means of ensemble and single-molecule spectroscopy. Proc. Natl. Acad. Sci. U.S.A. 98, 14398-14403.

62. Habuchi, S., Cotlet, M., Gensch, T., Bednarz, T., Haber-Pohlmeier, S., Rozenski, J., Dirix, G., Michiels, J., Vanderleyden, J., Heberle, J., De Schryver, F. C., and Hofkens, J. (2005) Evidence for the isomerization and decarboxylation in the photoconversion of the red fluorescent protein DsRed. J. Am. Chem. Soc. 127, 8977-8984.

63. Kredel, S., Nienhaus, K., Wolff, M., Oswald, F., Ivanchenko, S., Cymer, F., Jeromin, A., Michel, F. J., Spindler, K.-D., Heilker, R., Nienhaus, G. U., and Wiedenmann, J. (2008) Optimized and farred emitting variants of fluorescent protein eqFP611. Chem. Biol. 15, 224-233.

64. Gross, L. A., Baird, G. S., Hoffman, R. C., Baldridge, K. K., and Tsien, R. Y. (2000) The structure of the chromophore within DsRed, a red fluorescent protein from coral. Proc. Natl. Acad. Sci. U.S.A. 97, 11990-11995.

65. Turcic, K., Pettikiriarachchi, A., Battad, J., Wilmann, P. G. Rossjohn, J., Dove, S. G., Devenish, R. J., and Prescott, M. (2006) Amino acid substitutions around the chromophore of the chromoprotein Rtms5 influence polypeptide cleavage. Biochem. Biophys. Res. Commun. 340, 1139-1143.

66. He, X., Bell, A. F., and Tonge, P. J. (2002) Synthesis and spectroscopic studies of model red fluorescent protein chromophores. Org. Lett. 4, $1523-1526$.

67. Kummer, A. D., Kompa, C., Niwa, H., Hirano, T., Kojima, S., and Michel-Beyerle, M. E. (2002) Viscosity-dependent fluorescence decay of the GFP chromophore in solution due to fast internal conversion. J. Phys. Chem. B 106, 7554-7559.

68. Prescott, M., Ling, M., Beddoe, T., Oakley, A. J., Dove, S., Hoegh-Guldberg, O., Devenish, R. J., and Rossjohn, J. (2003) The $2.2 \AA$ crystal structure of a pocilloporin pigment reveals a nonplanar chromophore conformation. Structure (Cambridge) 11, 275-284.
69. Henderson, J. N., and Remington, S. J. (2006) The kindling fluorescent protein: a transient photoswitchable marker. Physiology 21, $162-170$.

70. Voityuk, A. A., Michel-Beyerle, M. E., and Rösch, N. (1998) Structure and rotation barriers for ground and excited states of the isolated chromophore of the green fluorescent protein. Chem. Phys. Lett. 296, 269-276.

71. Shu, X., Shaner, N. C., Yarbrough, C. A., Tsien, R. Y., and Remington, S. J. (2006) Novel chromophores and buried charges control color in mFruits. Biochemistry 45, 9639-9646.

72. Kummer, A. D., Kompa, C., Lossau, H., Pöllinger-Dammer, F., Michel-Beyerle, M. E., Silva, C. M., Bylina, E. J., Coleman, W. J., Yang, M. M., and Youvan, D. C. (1998) Dramatic reduction in fluorescence quantum yield in mutants of green fluorescent protein due to fast internal conversion. Chem. Phys. 237, 183-193.

73. Nienhaus, K., Renzi, F., Vallone, B., Wiedenmann, J., and Nienhaus, G. U. (2006) Exploring chromophore-protein interactions in fluorescent protein cmFP512 from Cerianthus membranaceus: X-ray structure analysis and optical spectroscopy. Biochemistry 45, 12942 12953.

74. Wilmann, P. G., Turcic, K., Battad, J. M., Wilce, M. C., Devenish, R. J., Prescott, M., and Rossjohn, J. (2006) The 1.7 A crystal structure of Dronpa: a photoswitchable green fluorescent protein. J. Mol. Biol. 364, 213-224.

75. Cinelli, R. A., Tozzini, V., Pellegrini, V., Beltram, F., Cerullo, G., Zavelani-Rossi, M., De Silvestri, S., Tyagi, M., and Giacca, M. (2001) Coherent dynamics of photoexcited green fluorescent proteins. Phys. Rev. Lett. 86, 3439-3442.

76. Marques, M. A., Lopez, X., Varsano, D., Castro, A., and Rubio, A. (2003) Time-dependent density-functional approach for biological chromophores: the case of the green fluorescent protein. Phys. Rev. Lett. 90, 258101.

77. Tozzini, V., and Nifosi, R. (2001) Ab initio molecular dynamics of the green fluorescent protein (GFP) chromophore: an insight into the photoinduced dynamics of green fluorescent proteins. J. Phys. Chem. B 105, 5797-5803.

78. Malo, G. D., Wang, M., Wu, D., Stelling, A. L., Tonge, P. J., and Wachter, R. M. (2008) Crystal structure and Raman studies of dsFP483, a cyan fluorescent protein from Discosoma striata. J. Mol. Biol. 378, 871-886. 